\title{
Coming of Age of IAP 2015 Growth Charts: The Way Forward
}

\author{
Anurag Bajpai $^{1}$ \\ Received: 12 June 2018 / Accepted: 13 June 2018 / Published online: 18 July 2018 \\ (C) Dr. K C Chaudhuri Foundation 2018
}

Growth charts are pivotal for holistic assessment of children. Besides identifying those needing further work-up for growth disorders, they provide framework for public intervention. Availability of country specific growth charts is essential to achieve this goal. This has been highlighted by studies that identified limitations of WHO standards in identifying growth disorders in different countries [1-3].

IAP 2015 growth charts represent a significant advancement in assessing growth of Indian children [4]. Developed using data of 33,148 children from 13 centers across the country the charts have become a valuable tool for pediatricians to assess growth of Indian children. Lack of field testing of the charts however remains an area of concern.

In this issue of the journal, Khadilkar et al., report their experience of field testing of IAP growth charts in 2175 Pune school children [5]. IAP 2007, IAP 2015 and WHO growth standards were compared in children from urban affluent, urban underprivileged and rural underprivileged sections of the society. The study expectedly observed over estimation of growth failure and undernutrition by WHO standards compared to IAP 2015 and IAP 2007 references. The prevalence of overweight/obesity observed with the IAP 2015 charts was higher by $27-54 \%$ than WHO and $36-54 \%$ by IAP 2007 standards (by 36-54\%) across the three groups. This would result in work-up of greater number of children for obesity related complications.

The study reaffirms the utility of IAP 2015 growth charts in assessing growth of Indian children, a few issues however remain unexplored. In particular the study is limited to one city and needs to be replicated in different regions of the country. Lack of work-up for etiology in children with growth failure and complications in those with overweight/obesity limits its clinical applicability. From a clinician's standpoint, a growth chart cutoff would be meaningful if validated for prediction of pathological cause (for growth failure) or morbidity (for obesity). The study while bolstering the confidence in using IAP 2015 charts, does not predict pathogenicity of the cutoffs. Studies designed to identify the likelihood of pathology in children with growth abnormalities using different standards is needed to answer the question.

In conclusion, while the study represents a much-needed validation of IAP 2015 growth charts, further field testing in different settings using functional outcomes are warranted.

\section{Compliance with Ethical Standards}

Conflict of Interest None.

\section{References}

1. de Onis M, Onyango AW, Borghi E, Siyam A, Nishida C, Siekmann J. Development of a WHO growth reference for school-aged children and adolescents. Bull World Health Organ. 2007;85:660-7.

2. Zong XN, Li H. Construction of a new growth references for China based on urban Chinese children: comparison with the WHO growth standards. PLoS One. 2013;8:e59569.

3. Rosario AS, Schienkiewitz A, Neuhauser H. German height references for children aged 0 to under 18 years compared to WHO and CDC growth charts. Ann Hum Biol. 2011;38:121-30.

4. Khadilkar V, Yadav S, Agrawal KK, et al. Revised IAP growth charts for height, weight and body mass index for 5- to 18-year- old Indian children. Indian Pediatr. 2015;52:47-55.

5. Lohiya N, Khadilkar V, Pawar S, Khadilkar A, Chiplonkar S, Jahagirdar R. Field testing of IAP2015 growth charts. Indian J Pediatr. 2018; https://doi.org/10.1007/s12098-018-2621-4.
Anurag Bajpai

dr_anuragbajpai@yahoo.com

1 Regency Center for Diabetes, Endocrinology \& Research, Kanpur, UP, India 